\title{
Da produção do lixo à transformação do resto
}

\section{From garbage production to residue transformation}

Abstract This research has a starting point the promising articulation between recyclable waste materials pickers and visual artists. Their intersection point is the way they reshape the remnants of the consumption society: waste pickers give new uses to objects bringing dignity to cast out materials, while visual artists reshape these subjectively refused objects into art, giving them new social value. This study tries to locate the continuity gap we created in regard to waste materials processing - what may they tell about us? Where do they stand at our social scale of values? Thus it becomes clear how waste objects aren't just technical realities but renewed values. Approaching waste objects with a logic that merely envisages their technical side would leave behind something they had as an essential part.

Key words Recyclable material pickers, Creativity and art, Social emancipation, Environmental education
Resumo A pesquisa tem como ponto de partida a articulação promissora entre o trabalho do catador de materiais recicláveis e do artista plástico. 0 ponto de interseção entre as duas categorias éa transformação dos restos da sociedade de consumo. Os catadores restituem a dignidade aos objetos desprezados. Já os artistas transformam o resto desprezado, o subjetivo, em algo nomeado socialmente como arte. 0 estudo busca se debruçar sobre o processo de descontinuidade que procuramos instituir com a produção de restos - o que eles dizem que somos? Qual o lugar que damos a el es em nosso laço social? Assim, acaba mostrando como os dej etos não são realidades técnicas, mas valores. Abordar a lógica do dejeto somente do ponto de vista técnico seria perder algo de essencial, que é ali enunciado.

Palavras-chave Educação ambiental, Catadores de materiais recicláveis, Criatividade e arte, Emancipação social
Escola Nacional deSaúde Pública, Fundação Oswaldo Cruz. Av. Brasil 4036/sala

905, M anguinhos. 21041-210 Rio deJaneiro RJ.

marta.velloso@ensp.fiocruz.br 
Introdução

No panorama do presente estudo, a pergunta central é: em que condições o desenvolvimento do potencial de criatividade deve contribuir ao processo de emancipação de comunidades? Para refletir sobre o cerne da questão, apresento conceitos de autores sobre o desenvolvimento do potencial de criação e a discussão sobre o processo de emanci pação social. 0 objetivo do estudo consiste em subsidiar a invenção de espaços com ambiente apropriado ao desenvolvimento da criatividade.

Os atores da pesquisa são catadores de materiais recicláveis e artistas plásticos, que se ocupam da transformação dos restos a partir de re síduos desprezados. Os instrumentos de coleta de dados abrangeram a pesquisa sobre vida e obra de artistas plásticos, a análise da documentação existente e produzida nas reuniões promovidas pela organização estudada e as entrevistas com os atores envolvidos - administradores, catadores de materiais e aprendizes da arte de transformação dos restos -, enriquecida pela observação participativa do pesquisador no local do estudo.

O cotidiano é fonte central de busca do esquecido, do rejeitado e também sinal dos descaminhos no ato de refugar. Os artistas transformam esse resto em imagens criadas pelo seu imaginário - criação desenvolvida por todos nós no dia a dia e reinventada na produção imagética. Os catadores nomeiam uma nova função para esse objeto ou simplesmente devolvem ao objeto desprezado a sua dignidade - passa a ser fonte, matéria-prima.

\section{Espaço criativo etransformação social}

A desigual dade social ea diversidadecultural pre sentes no Brasil sinalizam a necessidade de se pensar na inven ção de espaços para veicular educação e cultura. A mediação através de espaços destinados ao desenvolvimento do potencial de criatividade pode ser construída em escolas, centros de saúde e empresas, com a finalidade de resgatar diferentes culturas, propiciando o prazer na apreensão do conhecimento veiculado à diversidade cultural.

No presente estudo, vamos nos deter no "espaço criativo" em cooperativas de catadores de materiais recicláveis. Este "espaço" é aqui definido como espaço com ambiente apropriado, que o sujeito inventa para se inserir no mundo co- mum, ou seja, o ambiente facilitador à interação da sua singularidade com a realidade externa.

0 homem cria não apenas porque quer ou porque gosta, mas porque necessita. Ele só pode desenvolver-se como ser humano, ordenando, dando forma, criando. Segundo Winnicott ${ }^{1}$, no sujeito com capacidade cerebral einteligência razoável, existe a potencialidade para criar, mas a concretização detal potencialidadedependeráde um ambiente facilitador. Um ambiente facilitador é aquele que propicia algumas experiências básicas por um período de tempo suficientemente longo, experiências estas que poderiam se situar em duas áreas: (1) área da ilusão: a mãe-ambiente fornece ao bebê a experiência da onipotência; não há separação do eu-não eu, é o momento da ilusão que funda a experiência do ser sem interrupções insuportáveis, estabelecendo-se, assim, o verdadeiro ser e (2) área da desilusão: só depois de estabelecido o verdadeiro ser (na área da ilusão) que a desilusão poderá ser vivida de forma a criar um espaço potencial entre a mãe e o bebê. 0 objeto transicional, símbolo da união mãe-bebê, éo queocupará o espaço potencial no momento em que se dá a separação eu-não eu. Inaugura-se, aí, a capacidade de simbolizar, indispensável ao processo de sublimação.

É na área da desilusão e da criação do espaço potencial que se dá a atualização da capacidade de criar, que acontece primeiro no brincar, depois no espaço cultural, onde pode vir a ocorrer sublimação. Freud ${ }^{2}$ explicita sua preocupação com o brincar infantil na vida adulta, no artigo "Escritores criativos e devaneios", no qual, ao se perguntar sobre a atividade imaginativa, formula quetoda criança que brinca comporta-se como um escritor, na medida em que cria um mundo conforme suas ideias, ou, antes, organiza este mundo de uma forma que Ihe agrada; ela joga a sério e despende na sua brincadeira muita emoção. 0 que se opõe ao brincar não éa seriedade, mas a realidade.

M ais tarde, em "Formulações sobre os dois princípios do funcionamento mental", Freud ${ }^{3}$ justifica a existência da fantasia a partir da introdução do princípio da realidade. Segundo Freud, o artista afasta-se da realidade porque não consegue harmonizar-se com a renúncia às satisfações pulsionais e, na fantasia, autoriza-se a jogar com seus desejos eróticos esuas ambições - eleencontra, através disso, uma forma de retornar à realidade, transformando suas fantasias em verdades de um novo tipo, que são valorizadas pelos homens como reflexos preciosos da realidade. 0 artista, através da sua obra, consegue sensibili- 
zar os outros homens, na medida em que eles também sentem a mesma insatisfação com a renúncia exigida pela realidade. Tal insatisfação é gerada pela substituição do princípio do prazer pelo princípio da realidade, que é, em si, uma parte da realidade, ou seja, da realidade preestabelecida ou da ideologia social.

N este sentido é novamente Winnicott, o autor, que oferece 0 espaço que Freud procurava para a criatividade. Elenos fala de uma área intermediária de experiência- um espaço situado entre o interno e o externo, um paradoxo que, segundo ele, não precisa ser resolvido. No espaço onde Freud via uma possibilidade de escapar às imposições da real idade, Winnicott vêa criação como a única forma possível de se construir a realidade.

A criatividade, sob o ponto de vista terapêutico, tem importância em objetivar, concretizar, exteriorizar e extravasar, contribuindo para o desenvolvimento do sujeito. A tensão psíquica é um aspecto relevante para a criação, porque envolvea percepção consciente do homem, quenão é apenas de ordem física, mas também psíquica. De acordo com Ostrower ${ }^{4}, 0$ ato de criar, além de se constituir numa forma de descarregar a tensão psíquica, consiste também em sua constante renovação, ou seja, o ato decriar éum processo contínuo de descarregar e renovar a tensão psíquica. Assim, "a arte é mais potência renovada do que descarregada" ${ }^{4}$. Neste sentido, vale citar o artista Fernando Diniz, paciente do H ospital Pedro II (M useu da Imagem do Inconsciente): "O pintor é feito um livro sem fim".

A nossa sensibilidade é um canal aberto para as sensações. As nossas sensações são organizadas mentalmente através da percepção. A percepção é consciente; ela seleciona através da memória, das associações e das intenções, o que vai ser exteriorizado, ela cria forma para os fatos vividos. A partir do momento em que configuramos algo, excluímos muitas outras ideias e quando exteriorizamos o configurado, outras ideias vêm à tona. 0 processo criativo, portanto, ésimultaneamente delimitador e ilimitado. Citase novamente Ostrower ${ }^{4}$, que define o processo de criar, como um processo contínuo que se rege nera por si mesmo e onde o ampliar e o delimitar representam aspectos concomitantes, aspectos que se encontram em oposição e tensa unificação. A cada etapa o delimitar participa do ampliar. Assim, o processo de criar incorpora um princípio dialético que nos conduz à afirmação de Sousa ${ }^{5}$ "é a obra que produz o autor".

A passagem da matéria à percepção permanece envolvida em um impenetrável mistério. Tal passagem acontece mediante uma diminuição, i.e., a representação de uma imagem émenor do que a sua simples presença. Basta que as imagens presentes abandonem algo delas mesmas para que a sua simples presença se converta em representações. Segundo Bergson ${ }^{6}$, o queépreciso para se obter essa conversão não éiluminar o objeto e sim obscurecer certos lados dele, diminuí-lo da maior parte de si mesmo, de modo que o resíduo, em vez de permanecer inserido no ambiente como uma coisa, destaque-se como um quadro.

Três aspectos importantes, relacionados ao trabalho do artista, são apontados por Passeron 7 . Tais aspectos dizem respeito ao artistafrente a sua obra: (1) a obra por fazer coloca e sustenta uma posição questionadora, em que 0 artista é chamado a responder às interrogações que o trabalho Ihe coloca; (2) a exploração do homem pela sua obra, que pode ser descrita como um monstro a alimentar; (3) quando o trabalho é finalizado, a obra concluída não consegue responder totalmente às perguntas que a originaram. Tal término focaliza o caráter inacabado de todo processo de criação, no qual a obra concluída só vem a responder parcialmente.

O espaço criativo deve propiciar um ambientepara o desenvolvimento do potencial decriatividade do sujeito, que por sua vez vai capacitá-lo no processo de emancipação social.

A relação entre cidadania e subjetividade é bem complexa, envolvendo profunda reflexão sobre a responsabilidade e a singularidade. Santos ${ }^{8}$ explica que a subjetividade incorpora, além de direitos e deveres, particularidades de potencial infinito, que conferem cunho próprio eúnico à personalidade. $M$ as, os direitos e deveres em geral são elaborados, considerando os sujeitos em unidades iguais e passíveis de substituição.

$\mathrm{N}$ as administrações burocráticas, públicas ou privadas, os homens são intercambiáveis como força de produção. Na sociedade de consumo, se tornam consumistas e vítimas do desperdício. A igualdade da cidadania se contrapõe à diferença da subjetividade, i.e, no marco da regulação liberal, essa igual dade é profundamente seletiva, deixando de lado diferenças peculiares entre raças, gênero, culturas e a questão do sujeito.

As contradições geradas pelo próprio mercado hegemônico, frente a sua força produtiva, assim como o isolamento do movimento operário, ou a difusão social de novas formas de produção, propiciaram a emergência de novos movimentos sociais (NMS). Para Santos ${ }^{8}$, os N M S podem representar o ponto deinterseção na discussão destas contradições, que são a relação entre regula- 
ção eemancipação e a relação entre subjetividade e cidadania. Para 0 autor, a grande novidade desses movimentos sociais consiste na crítica construtivatanto da regulação social capital ista, como da emancipação social socialista, como foi definida pelo marxismo. Os NM S denunciam com ve emência os excessos de regulação da modernidade. Tais excessos atingem os meios de produção e a reprodução deles na vida das pessoas. 0 meio deprodução capitalista vem ocasionan do as guerras, a poluição, o racismo, o machismo e o consumismo. A consciência da população sobre essas drásticas consequências tem gerado um outro paradigma social, fundamentado não só nos bens materiais, mas principalmente na cultura e no bem-estar. Valores como cultura e bem-estar, em nome dos quais se lutam, são universais e globais, atingindo desde grupos sociais com interesses específicos - as mulheres, as minorias étnicas, os favelados e os homossexuais - até aqueles levados pelos interesses da humanidade no seu todo, como o movimento ecológico e os movimentos pacifistas. Entretanto, esses movimentos sociais devem permanecer atentos nas suas reivindicações, para não serem reduzidos a palavras chavões, caindo na rotina do consumo e setransformando em nova tensão.

Os novos movimentos sociais representam a afirmação da subjetividade sobrea cidadania, que deve ser fundada na expressão do novo ena atividade criadora, na luta pela emancipação pessoal, social e cultural. As novas demandas pautam-se por formas organizativas - democracia participativa - diferentes das que presidiam a luta pela cidadania - democracia representativa. Os seus protagonistas não são as classes sociais e sim os grupos sociais, ora maiores, ora menores queclasses, com contornos mais ou menos definidos, em vista de interesses coletivos por vezes muito localizados, mas potencialmente universalizáveis.

Os N M S, imbuídos das suas especificidades, também devem veicular ealimentar as singularidades dos sujeitos que o constituem, ou seja, a mediação entrea subjetividadeindividual ecoletiva deve estar sempre presente, uma vez que 0 grupo éformado por sujeitos. Tal mediação deve ser entendida como a integração do mundo interno do sujeito com o externo, i.e, a integração da sua singularidade com o seu grupo social.

$\mathrm{Na}$ busca desta interação, procurando transformar a sociedade, Guattari ${ }^{9}$ apresenta como alternativa a ecosofia - que consiste na articulação ético-política entre os três registros ecológicos: o meio ambiente, as relações sociais e a subjetividade humana. Segundo o autor, não será possível uma verdadeira resposta à crise ecológica a não ser que seja em escala planetária e com a condição de que se opere uma autêntica revolução política, social ecultural, reorientando os objetivos da produção de bens materiais e imateriais.

Esta revolução deverá engendrar não só a relação de forças visíveis em grande escala, mas também os domínios moleculares de sensibilidade, de inteligência e de desejo. A projeção amplamente imaginária da oposição, classe operária/burguesia, poderá ser substituída pelas novas problemáticas multipolares das três ecologias, ou seja, as antigas lutas de classes e os seus mitos de referência poderão ser substituídos pela complexa interação das três ecologias. Entretanto, tal substituição não émecânica nem automática, ela parece emergir deforma lenta, gradual e receptiva às mutações necessárias para a adaptação interativa entreas diferentes singularidadese o seu ambiente.

O processo de criação do sujeito está vinculado ao seu desenvolvimento emocional, a sua sensibilidade e à cultura. Quando abordamos 0 ser criativo, devemos pensar na interação da cultura no desenvolvimento do seu potencial decriatividade. Segundo Santos ${ }^{10}$, a concepção multicultural de direitos humanos pode servir como instrumento para se atingir a emancipação social. Os direitos humanos só poderão desenvolver o seu potencial de emancipação quando se tornarem verdadeiramentemulticulturais. As versões emancipadoras do multiculturalismo baseiam-se no reconhecimento das diferenças e da coexistência de uma vida em comum, para além das diferenças de vários tipos. As condições, para a transformação dos direitos humanos num projeto cosmopolita, fundamentam-se na promoção de diálogos interculturais, sobre preocupações semel hantes e sobre critérios políticos para distinguir política progressista da conservadora, capacidade de desarmee emanci pação da regulação. Santos e Arriscado ${ }^{11}$ nomeiam de hermenêutica diatópica estediálogo intercultural - que consiste na prática de interpretação e de tradução entre culturas, através das quais se amplia a consciência da incompletude de cada cultura envolvida no diálogo ese cria a disponibilidade para a elaboração de culturas híbridas, de dignidade humana mais rica e mais amplamente partilhada. A hermenêutica diatópica, visando à escolha da cultura mais adequada, deve adotar dois imperativos interculturais: (1) das diferentes versões deuma dada cultura, deveser escol hida aquela que representa o círculo mais amplo de reciprocidade dentro dessa cultura, a versão que vai 
mais longe ao reconhecimento do outro e (2) os grupos sociais, ou a pessoa, têm o direito de serem iguais, quando a diferença os inferioriza, eo direito a ser diferentes, quando a igualdade os descaracteriza.

Os direitos humanos, elaborados para preservar a dignidade do homem, devem respeitar as diferenças peculiares de uma raça, do gênero, de um determinado segmento social, de uma outra escol ha grupal e das vicissitudes do sujeito. N estas condições, e seguindo os imperativos interculturais da hermenêutica diatópica, os direitos humanos poderão ser utilizados como instrumentos para a emancipação social.

0 desenvolvimento do potencial de criação do sujeito está relacionado a um ambiente propício, ou seja, um ambiente onde ele possa ter espaço para desenvolver a sua singularidade e reintegrá-la à realidade externa através de atividades culturais, sociais e políticas. Esse espaço é, pois, um interno imerso e fundado no mundo. $\mathrm{N}$ a nossa vida, esses momentos internos e externos se justapõem; alguns desaparecem, outros emergem e é a criação desses momentos o que permite a afirmação do nosso ser no mundo. Segundo M omberger ${ }^{12}$, a construção identitária do sujeito acontece mediante a dialética de tais momentos, que são opostos e complementares. Os momentosinternos do sujeito, quando sentidos pela mai oria dos homens, podem ser transformados em realidade. A criação de uma outra realidade poderá vir à luz, através da manifestação dos sentimentos e das emoções de sujeitos. Assim, a realidade interna de sujeitos, interagindo com a realidade externa, pode contribuir para o processo de emancipação de pequenos grupos, comunidades ou sociedades. A partir desses fatores essenciais para o desenvolvimento da criatividade, podemos gerar o que Santos e Rodrigue ${ }^{13}$ se referem como "recriação da promessa de emancipação social".

A sociedade contemporânea vem sofrendo transformações de valores. Segundo Bauman ${ }^{14}$, os valores da modernidade estão perdendo sua solidez, transformando-se em líquidos, mudança que ocasiona instabilidade e crise social, surgindo a seguinte indagação de preocupação: que valores devem ser acrescentados para se al cançar um futuro previsível e promissor?

A transição de val ores queestamos vivenciando na modernidade afeta os mais variados aspectos da nossa vida. A função da sociologia, segundo Bauman, éa de despertar a autoconsciência, a compreensão e a responsabilidade individual, a fim de promover a autonomia ea liberdade.
O homem, para ter acesso as suas reivindicações, deve estar inserido na sociedade. Bauman explica a diferença entre necessidade de libertação objetiva e subjetiva. Na libertação subjetiva, o sujeito mantém seus desejos e seu potencial de imaginar de forma infinita, enquanto que sua capacidade de ação é delimitada. Já na li bertação objetiva, o desejo, a imaginação e a ação se encontram em perfeito equilíbrio - nesse caso, a libertação éum slogan sem sentido, poisfalta força motivacional. Pode ser que o desejo de melhorar tenha sido frustrado ou nem sequer tenha tido oportunidade de aparecer - assim como a pressão do princípio da realidade exercida sobre a busca humana pelo princípio do prazer e da felicidade, segundo Freud.

A práxis de atividades criativas vai contribuir ao preenchimento da necessidade de liberdade subjetiva. A imaginação e o desejo do sujeito são infinitos e sua ação deve ser conquistada. 0 "espaço criativo" deve ampliar a ação do sujeito, no sentido de funcionar como um ambiente propício ao desenvolvimento do seu potencial de criatividade. Tal espaço, físico e concreto, também deve ser veículo facilitador de possi bilidades abstratas e subjetivas inerentes à capacidade de desejar e de imaginar inatas do sujeito.

A criatividade do sujeito surge no espaço intermediário entreo objetivo eo subjetivo, entreo mundo interior e o mundo comum. Nos momentos de criação, o sujeito vivencia o sentimento de completude, ele experimenta o equilíbrio entreos dois princípios do funcionamento mental - o prazer e a realidade.

No momento de completude do sujeito, o desejo ea imaginação encontram um espaço com ambiente propício à ação - no caso, o espaço criativo.

\section{Artistas plásticos: os catadores de resíduos}

A partir de um célebre quadro de M illet, "As respigadoras", no qual mulheres catam no campo as sobras da colheita do milho, o filme de Agnès Varda, "Os catadores e eu" (Les glaneurs et la glaneuse), éum olhar sobrea persistência dos respigadores, ou seja, daqueles que vivem da recuperação de coisas (resíduos, restos, sobras) que os outros não querem e deixam para trás.

Nesse sentido, Agnès se coloca como a própria catadora que, experimentando uma pequena câmara digital, se assume como uma recuperadora de imagens desprezadas ou não valorizadas pela sociedade de consumo. 
A cineasta ainda constrói uma anal ogia entre a sobra e os objetos, que escolhemos em nossas viagens como recordações. Ela abre um baú evai retirando deleos objetos queescol heu para guardar como lembranças. Tais objetos também não possuem valor econômico esocial, mas pessoal e afetivo. Assim, Agnès procura mostrar esta lógica de valores ao fotografar batatas em forma de corações, que pelo seu aspecto irregular são desprezadas pelos colhedores (coliédor), mas acoIhidas com prazer pelos catadores (glaneurs) e pelos artistas em busca da necessidade ou da estética esquecida.

0 homem, através da arte, pode alcançar a dimensão do seu desejo que, impedido de vir à luz, se sublima no fazer da obra. N este momento, metransporto à obra de Farnese de Andrade. Antes de falar da obra desse artista, é necessário falar da sua vida. A interação entre a vida e a obra do artista é tão intensa, que não seria possível falar de uma sem tocar na outra - com a unicidade do seu olhar, ele veicula, através da obra, as tragédias ocorridas no mundo e o sofrimento de sua perda na infância. Observamos na matéria-prima usada pelo artista - bonecas de louça, fotografias defamília, móveis antigos, oratórios, madeiras envelhecidas - que ele constrói sua arte com os resíduos do passado, ou melhor, com o resto ou a sobra que permaneceu da sua infância. Farnese foi o sexto filho de oito irmãos. N asceu na cidade de Araguari, em M inas Gerais, e seu pai era tabelião no cartório herdado do avô. Sua mãe confeccionava grinal das de tecido para noivas - ofício que passou às filhas. Antes do seu nascimento, seus pais perderam dois fiIhos numa enchente, tragédia que marcou profundamentesua vida. A pesar de não ter conhecido seus irmãos, reviveu, através dos seus pais, a lembrança da existência e a profunda tristeza da ausência. Inicialmente, sua obra consistia em desenhos figurativos e gravuras abstratas. $M$ ais tarde, catando objetos encontrados na praia, começou uma nova fase de montagens.

0 artista andava na praia, catando os objetos que encontrava. $E$, no prazer de caminhar e catar objetos, descobriu a beleza de um pedaço de madeira sujo de óleo e desgastado pelo mar - envernizou esse achado e, a partir daí, fez dos seus passeios na praia uma procura de matéria-prima para a construção de sua obra. Também se tornou um especialista em marés. A busca e o encontro de materiais variavam de acordo com as marés - a marécheia trazia um material diferente da vazia. Assim, el e conta esse episódio da sua vida: [...] 0 caso das bonecas é mais engraçado. Há uma espécie de desova, como das tartarugas. Às vezes, passam-se dois ou três meses sem aparecer praticamentenenhum corpo ou cabeça. De repente, começo a achar cinco ou mais por dia: santos de gesso usados como oferenda ou macumba, além de objetos de plásticos os mais variados [...] ${ }^{15}$.

A esta fase, 0 artista denominou de fase dos desgastados. Depois do uso das primeiras vasiIhas de vidro, passou a comprar em lojas de materiais de segunda mão e de antiguidades, assim como em depósitos de demolição e ferros velhos. Muitas vezes, ele trabalhava com materiais perecíveis e, por isso, tinha de protegê-los, usando uma redoma. No começo, as redomas eram de vidro ou provenientes de peças de laboratório. M ais tarde, ele descobriu o poliéster e adotou esse material.

O vídeo sobre a vida e a obra de Farnese (o curta-metragem "Farnese - caixas, montagens e objetos", de Olívio Tavares de Araújo, que recebeu o primeiro prêmio no Festival cinematográfico de Brasília, em 1971 erepresentou o Brasil no Festival de Cannes em 1972) mostra a sua casa, onde viveu entre a morbidez ea imaginação criativa. 0 artista fala sobre a situação do ser humano, que éimpossibilitado de al cançar a felicidade porque se sabe mortal. 0 homem sabe que vai morrer, por isso está condenado a esperar a morte, de que tem medo. 0 homem só pode ser feliz se acreditar na possibilidade de uma outra vida, na continuidade da sua existência. Segundo ele, 0 ser humano viveaprisionado pelo terror dabomba atômica ou da guerra, que pode destruí-lo definitivamente. 0 aprisionamento do ser humano destrói a sua percepção de humanidade.

Siron Franco, artista plástico nascido em Goiânia, fez da sua obra um meio de expressar a verdade dos acontecimentos - seus sentimentos, emoções e contestações são fortemente transmitidos à população. Para 0 artista, a população deve ter acesso a outro veículo de comunicação além daquel es convencionais como os jornais ea televisão - queinformeos acontecimentos na sua completude, ou seja, não só aquilo que vemos através do fato narrado, mas algo que percebemos com a nossa alma. Perceber um fato com a alma humana está cada vez mais difícil no mundo de materialidade em que vivemos. Logo, 0 artista e a sua obra possuem um papel determinante na nossa sociedade- el es podem constituir o elo entre o consciente e $o$ inconsciente, entre 0 objetivo e o subjetivo. Falo do artista e da sua obra, uma vez que 0 artista vai se descobrindo no fazer da sua obra e esse fazer não seria possível sem a sua presença. 
Quando ocorreu o acidente de contaminação radioativa pelo césio 137 , Siron, que morava na cidade de São Paulo, foi imediatamente para Goiânia. Ele nasceu em Goiânia e morou por 22 anos no bairro Popular, na Rua 74, próxima à Rua 57, onde aconteceu a tragédia. 0 motivo do seu retorno à cidade natal foi o de, através da sua obra, passar informações íntegras à população apesar das suas obras anteriores serem portadoras deum caráter crítico e denunciador, nunca nenhuma delas, até a série da Rua 57 ou a série do césio, expressaram de forma tão contundente essas características, ou seja, uma bandeira de luta explícita e objetiva. Assim, mobilizado pelo seu ideal de luta, passou a frequentar o bairro, assumindo a função de informar e denunciar os fatos e os fatores que poderiam estar relacionados ao acidente- concedeu inúmeras entrevistas, sinalizando para a profundidade do ocorrido, criou uma série de desenhos, pinturas e esculturas, realizou uma exposição em favor das vítimas, criou trezentas máscaras para uma manifestação de protesto e participou de várias manifestações contrárias à política nuclear brasileira ${ }^{16}$. 0 trágico acidente atômico teverepercussão internacional, revelando a ausência ea incompetência do Brasil no que diz respeito ao tratamento específico exigido para o lixo atômico. Em 17 desetembro de 1987, foi encontrada, nos depósitos delixo do I nstituto de Radiologia de Goiânia, uma cápsula de césio pesando cerca de cem quiIos. Dois sucateiros - Roberto Santos Alves e Wagner M ota Pereira - encontraram o estranho objeto e o venderam ao dono do ferrovelho, $\mathrm{De}$ vair Alves Ferreira. No ferrovelho, a cápsula foi aberta e, depois da ruptura de sua camada de chumbo, do seu interior foi retirado um objeto do tamanho aproximado de um ovo e com um intenso brilho, chamado pel os físicos de alma de irídio. Esta denominação é atribuída à camada selante, usada para envolver o material radioativo. A camada, composta por uma rígida substância, teve que ser rompida com os golpes persistentes de uma marreta, operação que durou uma noite. Quando finalmente conseguiram abrir a camada, encantados com o brilho do seu conteúdo, Devair e seus ajudantes pensaram ter em mãos algo de grande valor. Desconhecedores da letalidade que a substância portava e fascinados pelo pó translúcido, fizeram-no passar de mão em mão. A esposa de D evair, M aria Gabriela Ferreira, passou o pó pelo seu corpo, como se fosse uma purpurina. Leide das Neves, uma menina de seis anos, ingeriu o pó junto com um alimento. A pós alguns dias, as pessoas que tiveram con- tato com o pó apresentaram os sintomas da intoxicação por radiação. M aria Gabriela relacionou a presença dos sintomas com a descoberta da substância e levou a cápsula para a Coordenadoria de Vigilância Sanitária da Secretaria de Saúde do Estado - local onde foi diagnosticada a contaminação pelo césio 137. Foram contaminadas 244 pessoas. Quatro delas morreram logo após o contato direto com a cápsula de césio. $M$ ais de cem pessoas passaram a receber atendimento médico na Fundação Leide das Neves fundação criada naquela ocasião para atender as vítimas da contaminação e que levou o nome da segunda vítima fatal, uma criança - ecatorze pessoas, em estado grave, foram transferidas para um hospital no Rio de Janeiro ${ }^{16}$.

Siron Franco, na sua série Césio ou Rua 57, usou nos seus quadros uma gama incrivelmente pequena de pigmentos - a terra de Goiânia - que se apresenta num impressionante tom vermeIho-ferrugem, enriquecida pelas tonalidades das tintas em cores prata, preto e azul. Com essas cores, 0 artista busca representar a contaminação pela radiação. Também utilizou uma simbologia para designar a letalidade do césio eo modo de se proteger das suas vítimas - o símbolo da radioatividade ou o triângulo negro. 0 artista resolveu usar a terra como pigmento quando começaram os rumores de que os produtos de Goiânia estavam contaminados pelo elemento radioativo ${ }^{17}$.

Frans Krajcberg nasceu em Kozienice, na Polônia. Seu pai era um modesto comerciante esua mãe, militantecomunista. Em 1939, encontravaseem Czestochava, quasena fronteira com a Alemanha, quando o exército alemão invade a Polônia. Estoura a Segunda Guerra Mundial. Volta à sua cidade natal, mas já não encontra sua família - seus pais e quatro irmãos - que mais tarde foi exterminada em campos de concentração. Preso, consegue fugir e integra-se ao exército russo na Polônia. Adoece e, quando internado, durante 0 período de recuperação, começa a pintar. Em 1945, estuda na Escola de Belas Artes de Stuttgart na Alemanha, com Willy Baumeister - que fora professor da Bauhaus. Em 1948, viaja para Paris, onde vive na mais extrema miséria e, depois de quatro meses, com um bilhete de terceira classe, embarca para o Brasil. Por razões de sua história pessoal, escolheu o Brasil como sua pátria. Nunca foi um nacionalista, sua pátria é a natureza.

0 trabalho desse artista é construído a partir dos restos da destruição ambiental - folhas, sementes, raízes etroncos carbonizados pelas queimadas. Ele reforça a ideia de que a sobrevivência 
da humanidade depende diretamente da sobre vivência do planeta, chamando a atenção do homem sobre a impossibilidade de viver distante da sua natureza. Ao chegar ao Brasil, se integra à diversidade da nossa flora, com suas árvores centenárias, às folhas, às flores, às sementes, aos pássaros, aos rios, ao mar e aos sons da floresta. Quando conheceu N ova Viçosa, na Bahia - local onde escolheu para habitar e onde teve a mesma sensação que em Cata Branca, M inas Gerais - ele dançou, chorou e se perguntou: como captar e expressar a vida dessas formas, a diversidade das espécies vegetais, as alterações e vibrações que elas provocam em mim?

Quando 0 artista se instalou em Cata Branca, estava imbuído de um duplo e firme objetivo - compreender seu relacionamento com a natureza e lutar contra a pintura impregnada pelo academicismo. Começou por substituir as bisnagas de tintas pelos elementos in natura - terra, pigmentos e pedras de diversos formatos, tamanhos e cores. M as esses elementos ain da estavam fixados à moldura. A arte não deveria permanecer limitada a duas horizontais e duas verticais. Pensando numa nova forma para a arte, ele descobre a força das raízes. As raízes, ao contrário das flores, possuem um potencial de vida ainda em latência e saem de dentro daterra, ávidas pela luz. As flores, apesar da sua beleza, são frágeis, pois já alcançam o seu fim no ciclo da vida ${ }^{18}$.

\section{Espaço criativo eorganização de catadores}

Este item descreve o estudo realizado em uma associação de catadores de materiais recicláveis (ASM ARE), localizada na cidade de Belo Horizonte, em M inas Gerais, tendo apoio da Companhia de Limpeza Urbana da Cidade e de mediadores, que atuam junto aos associados.

$\mathrm{Na}$ associação, entrevistamos a administradora (catadora fundadora), três orientadores das "oficinas de arte a partir do lixo", sendo um deles o precursor, e três associados. A análise das entrevistas foi enriquecida pela observação participante do pesquisador no local da pesquisa ${ }^{19}$. 0 período da pesquisa na associação foi julho de 2002. Os roteiros das entrevistas semiestruturadas, segundo Velloso ${ }^{20}$, foram elaborados de acordo com duas categorias estabelecidas: (1) administradores, orientadores e mediadores das associações e (2) catadores de materiais recicláveis e aprendizes da arte de reciclar.

Aos primeiros foram dirigidas as seguintes questões: início da associação (data da funda- ção, número de associados, mediadores); número atual de associados; produtividade (individual ou coletiva); requisitos para se associar (exigências da associação e o que ela oferece); venda do material arrecadado (empresas de reciclagem ou atravessadores); destino final do lixo na cidade; como é divulgado o trabalho da associação (meio de aproximação dos catadores, se existe algum trabalho da associação para trazêlos até ela); existência de al gum trabalho deartea partir do lixo; os catadores fazem al gum curso antes de setornarem sócios; quais os benefícios propiciados aos associados (cesta básica, aposentadoria, creche, escola, férias, décimo terceiro salário, serviços de saúde, moradia); quais os documentos existentes na associação (jornal, revista, estatuto, boletim, página na internet).

Aos segundos, foram dirigidas as seguintes questões: como eles percebem o trabalho; como as pessoas percebem o trabal ho deles; semprefoi catador ou já teve outra ocupação; quais as possíveis melhorias para o associado; como preservar a associação; como se sentetrabalhando com material desprezado, que étransformado em um novo objeto reutilizável ou decorativo.

Os catadores tiveram o apoio e a mediação da Pastoral de Rua da Igreja Católica de Belo Horizonte. Eles queriam trabalhar, mas não conseguiam o aval da prefeitura. No início, começaram a se reunir debaixo do viaduto, depois no quintal (debaixo das árvores) de uma casa velha no bairro do Barro Preto. M ais tarde, um padre, da Casa do Trabalhador, emprestou a casa para as reuniões e assim foi surgindo a ideia de se fundar uma associação.

Os catadores começaram a fazer passeata na porta da Prefeitura de Belo H orizonte. Com esse movimento e por meio dos contatos com as autoridades afins, conseguiram o seu primeiro galpão (onde já moravam clandestinamente) e, assim, puderam iniciar o processo de armazenamento do papelão com o aval da prefeitura. A pós cinco meses, eles verificaram as tabelas de preço para o papelão e negociaram a sua venda pelo melhor preço de mercado, formando o capital de giro.

Antes da associação, os catadores ganhavam o carrinho dos atravessadores de materiais recicláveis para quem eles trabalhavam e vendiam esse material por preço já estipulado. Depois de associados, o processo de trabalho foi se transformando: os catadores começaram a ter consciência dos seus direitos de cidadão - creche e escola para os filhos, moradia, melhores condições de trabalho e de remuneração. H oje, no gal- 
pão, onde há doze anos já funciona a associação, o catador chega com o seu carrinho carregado de material. N esse espaço, ele separa os diferentes materiais recicláveis, que são prensados, pesados e vendidos pelo preço de mercado às empresas de reciclagens ou às intermediárias no processo. A produção é individual, ou seja, cada um recebe deacordo com a sua produção diária, que é registrada num microcomputador.

Existe uma parceria com a prefeitura, ela faz o convênio, mas é a associação quem administra, ou seja, a prefeitura cedealgunsfuncionários para a área administrativa, mas eles trabalham em conjunto com os catadores. A associação foi fundada em 1990, possuindo registro de fundação e estatuto. Ela tem um outro gal pão, que é um grande espaço físico, onde trabalham mais de cem pessoas. N este gal pão, os catadores recebem os caminhões da col eta seletiva do lixo (quatro da prefeitura e dois alugados pela associação) e fazem a sua triagem, separando os diferentes tipos de resíduos, enquanto os catadores do primeiro galpão saem com suas carrocinhas para catar o lixo nas ruas.

Para tornar-se sócio, o catador deve pagar a mensalidade de três reais e fazer um curso de capacitação com duração de três meses, período em que recebe orientações sobre a importância do seu trabalho para a sustentação do meio ambiente e toma conhecimento das normas da associação quedevem ser obedecidas. A associação conta com 366 associados, mas, incluídas suas famílias, são 1.500 ben eficiados. A associação está levando sua experiência para 33 municípios, para retirar os catadores do lixão e trazêlos para a organização. As assistentes sociais vão até os lixões e instruem os catadores, visando à melhoria das suas condições de vida e trabalho.

$\mathrm{Na}$ associação, já está em andamento o projeto de uma creche, onde as mães que trabalham no gal pão poderão deixar suas crianças. Entre as catadoras, é comum, logo após o parto, a retomada do trabalho. Com isso, o recém-nascido vai para a rua com a mãe, transportado no carrinho de coleta. Algumas escolas possuem convênio com a associação, ou seja, algumas vagas são reservadas aos filhos dos catadores. Na própria associação, há um treinamento em marcenaria para adolescentes. N este treinamento, eles aprendem técnicas para recuperação de móveis - que são descartados no lixo ou doados por instituições e domicílios -, transformando-os em belas peças decorativas. Na marcenaria, também são construídos os carrinhos da associação, identificados com seu nome, telefone e endereço. Os associados ganham o carrinho eo uniforme. Eles ainda não possuem carteira assinada, convênio com serviços de saúde, pensão ou aposentadoria e falam sobre a dificuldade do reconhecimento da profissão "catador de lixo".

A maioria dos catadores fez parte da população de rua. Eles viviam em condições de miséria no local onde atualmente funciona a sede da associação, que vem fortalecendo, perantea população, a imagem deles como trabal hadores.

Além dos galpões de triagem, a associação também desenvolve atividades culturais, criativas e lúdicas. Ao atravessar a rua do primeiro gal pão, visualizamos um prédio de três andares, conhecido como Bar Reciclo. Estebar, quefunciona no andar térreo do edifício, foi todo construído com material reaproveitado - cadeiras, mesas, bal cão e objetos de decoração. N ele, também há uma pequena loja destinada ao comércio de objetos, feitos pelos artesãos e artistas da associação, com papel reciclado e com outros materiais reutilizados. N o bar, em geral à noite, acontecem atividades culturais, tais como espetáculos musicais, reuniões e encontros. Atualmente, 0 espaço está sendo frequentado pelo público de Belo H orizonte que aprecia a criatividade veiculada pela diversidade cultural, como a boa música e os objetos artesanais.

0 prédio ondefica o Bar Reciclo é uma parceria da associação com a prefeitura. Seu principal objetivo é acolher a população desabrigada, que é encaminhada pela prefeitura, pela pastoral de rua ou pela própria associação para os setores de aprendizado - corte e costura, oficina de papel reciclado eatividades criativas, como pintura e escultura. Eles aprendem um ofício sob a orientação de artistas plásticos e são levados ao abrigo da cidade. Também já está em andamento um setor de informática. $\mathrm{Na}$ fase inicial do aprendizado, el es ganham uma menor remuneração. M aistarde, quando jáfazem do ofício o seu meio de subsistência, além de ganharem mais, são incentivados ou indicados a buscar novas oportunidades de trabalho.

A parte lúdica é revivida todos os anos, na preparação das fantasias, nos ensaios do bloco da associação e no carnaval da cidade. As fantasias são elaboradas pelo orientador da oficina de arte (artista plástico) em conjunto com o catador (dono da fantasia). As fantasias e os adereços do bloco são feitos com material descartado.

Os associados falam das vantagens da moradia, da alimentação, dos instrumentos de trabalho, dos direitos trabalhistas, de escola e creche para os filhos. Eles possuem um local de tra- 
balho para a família, onde podem armazenar os resíduos coletados para depois selecioná-los e vendê-los. Também existem algumas vagas reservadas em escolas e a possibilidade deuma formação profissional para os filhos - trabalhar como marceneiro, prática que adquirem reformando móveis usados. Além disso, eles têm re feições por um preço acessível e, no Bar Reciclo, música ao vivo, teatro e acesso às atividades artísticas. Durante o carnaval, eles participam da elaboração das fantasi as e da organização do bloco da associação.

A organização vem fortalecendo a sua imagem de trabal hador perante a população. A situação de desamparo, na qual se encontravam antes do processo associativo, está sendo trabal hada mediante atividades criativas, culturais e lúdicas, desenvolvidas no espaço criativo e no Bar Reciclo.

A associação é respeitada na cidadee já reconhecida pelos catadores de outros estados como referência nacional. A população identifica os carrinhos dos associados e contribui na entrega do material a ser reciclado ou reformado. Apesar do incentivo dispensado pela prefeitura na organização da associação, ainda observamos, pelas ruas da cidade, catadores que preferem trabaIhar como autônomos ou independentes. A catadora, uma das fundadoras, conta que alguns associados retornam aos depósitos de lixo, onde viviam antes de se associarem. Ela explica que existe atéum trabal ho das assi stentes so ciais para trazer esses catadores de volta para a associação, onde possuem um local de trabalho mais adequado, uniforme, instrumentos de proteção e recebem abrigo ou casas para morar. Esta opção nos leva a refletir sobre a organização em questão, isto é, como criar mecanismos de inserção sempre atuantes?

O processo de inserção social começou a ser trabal hado através das oficinas de "arte a partir do lixo". A artista plástica Águida Zanon desenvolveu um trabal ho para melhorar a autoestima dos catadores e daqueles que lá foram acolhidos. Ela realizou oficinas de arte na associação durante oito anos, buscando, através do diálogo com eles, descobrir alguma festa popular que os despertasse para o processo de criatividade.

As oficinas eram desenvolvidas utilizando 0 material que eles catavam, criando uma outra linguagem para esse material. "Trabalhar usando 0 material reciclável étrabalhar a autoestima do próprio catador", diz a artista, que trabalhou com diversas faixas etárias, desde crianças bem pequenas até idosos. A festa popular que despertou maior interesse foi o carnaval. A artista começou a construir asfantasias decarnaval ecada um participava da escolha e elaboração da sua fantasia.

A meta da oficina, segundo a artista, é desenvolver a criatividade como meio de inserção social. Assim, através desse processo, o catador vai percebendo que ele pode ser um reciclador, ou seja, ele pode ascender a uma outra condição social - elevai percebendo quesua sobrevivência pode se dar a partir da transformação do lixo em matéria-prima, gerando um novo produto. Atualmente, dois artistas plásticos dão continuidade ao trabalho da artista precursora, com os associados. Eles trabalham com os catadores e com os desabrigados.

Wilson, ex-desabrigado, foi acolhido pela associação há quatro anos. Quando criança, ele passou pela Fundação Estadual de Bem-Estar do M enor (Febem), onde iniciou os seus primeiros contatos com o trabalho artesanal. Fala que se sente muito bem na associação, principalmente na sua interação com o grupo de trabalho. Sofreu muito na primeira infância, mas hoje se sente vitorioso. Considera esta vitória como dele próprio, que lutou muito para superar os maus-tratos sofridos no passado. A preendeu a técnica da arte e hoje é especialista na criação de oratórios.

Teobaldo, ex-desabrigado, nasceu e cresceu na cidade de Recife e chegou a trabal har como vigilantena polícia militar, mas fala sobre as consequências do uso da bebida al coólica na sua vida e do seu processo de adaptação na associação. No início, trabalhou como catador, mas não se adaptou. Foi transferido para a oficina de criatividade, onde começou desenhando e depois esculpindo e pintando. Escutou a história da associação e retratou os acontecimentos em grandes telas coloridas. Explica a importância de possuir um recanto, respeitado pelos colegas, com seus instrumentos de trabalho. Fala da sua necessidade de estar sempre criando algo e reconhece 0 apoio da organização para o desenvolvimento do seu potencial artístico.

\section{Consideraçõesfinais}

Todo processo de produção gera restos, que vão sendo acumulados em depósitos de lixo. Ao criarmos al go, sentimos que nosso processo de criação está encerrado quando eliminamos a sobra que não pôde ser aproveitada na elaboração da obra. Esta sobra é enviada para bem longe do nosso convívio, para que possamos esquecer os problemas originados pelo seu excesso. Bau- 
man 21, no seu livro "Vidas Desperdiçadas", faz uma analogia entre o lixo produzido em excesso pela sociedade de consumo e os seres humanos marginalizados. Estes seres são considerados problema, como o próprio lixo produzido em excesso. Eles estão sobrando, el es são reconhecidos como aqueles que não deveriam existir, ou seja, são "redundantes" para a sociedade. A situação desumana envolve os refugiados, os prisioneiros, os miseráveis ou todos aqueles que são tratados como resto - não sabemos o que fazer com eles e queremos distância, pois nos sentimos ameaçados pela sua presença. 0 autor fala que já não há espaço social para os párias da modernidade, os não adaptados, os banidos, os marginalizados, a sobra humana produzida pela sociedade de consumo. No entanto, ressalta a importância do papel social desempenhado pelos catadores de lixo - eles reavivam a linha de fronteira entre normalidade e patologia, saúde e doença, desejável e repulsivo, aceito e rejeitado, ou seja, o dentro e o fora do universo humano. Esta fronteira precisa de constante vigilância, porque não é uma fronteira natural - não há montanhas altíssimas, oceanos sem fundo ou gargantas intransponíveis separando o dentro do fora, ou melhor, não é a diferença entre produtos úteis e refugo que demarca a divisa. Ao contrário, éa divisa que invoca a diferença entre eles - a diferença entre 0 admitido e 0 rejeitado, 0 incluído eo excluído.

0 alumínio proveniente das latas de refrige rantes e de cervejas é reciclado e retorna ao ciclo da vida como objeto de valor. Contudo, muitas latas ainda são descartadas como lixo nos depósitos. Entretanto, cabe ressaltar que elas têm sido cada vez mais utilizadas como matéria-prima. Assim como o alumínio, o papel, o papelão e o plástico estão sendo valorizados como materiais recicláveis; o catador responsável pela sua busca também deveser reconhecido.

A associação estudada tem apresentado resultados positivos com a criação das oficinas de "artea partir do lixo". Neste sentido, fica registrada a importância de se criarem espaços com ambiente apropriado para atender às especificidades de cada comunidade, nos quais permaneçam 0 respeito à singularidade de cada componente do grupo e a sua interação dinâmica com o coletivo.
O Bar Reciclo, onde começou o espaço criativo da associação, originou o Reciclo II, que está localizado em um bairro central da cidade. 0 Reciclo II possui um bar com alimentos naturais, uma horta e uma loja, que vende os objetos criados pelos artistas e artesãos da ASM ARE. 0 público de diferentes faixas etárias e de diversos segmentos sociais é atraído pela boa alimentação e pela criatividade dos objetos comercializados.

Assim como 0 artista, o catador pode desenvolver sua capacidade inata de criação, alcançando sua pertença social. Entretanto, torna-se necessário que tanto a referida categoria como a sociedade sofra transformações simultâneas no seu aspecto econômico, político ecultural.

A criação de soluções para resolver problemas ambientais veiculados por resíduos, desdea produção até o seu destino final, deve partir de cada pessoa, ou seja, o singular deve interagir com o coletivo formado pelo consenso entre as diversas e diferentes culturas, desenvolvendo medidas a favor da saúde pública no âmbito local e global. Entretanto, cabe lembrar que esse todo não é constituído pelo simples somatório das suas partes, uma vez que cada parte continua mantendo a sua singularidade.

O homem deixa seu resto e sua marca por onde passa. A procura do homem é infinita, seu desconhecimento é ilimitado e a desordem faz parte da sua busca pelo saber. Assim, a passagem do homem na história do mundo permanece pelas suas sobras - [...] lá onde encontramos uma acumulação titanesca deconchas deostras, não pode manifestamente deixar de ser que homens passaram por lá [...] lá onde há uma acumulação de dejetos em desordem há homem [... ${ }^{22}$.

O homem, no decorrer da história, aproxima-se cada vez mais da disciplina e da manutenção, distanciando-se do desejo. Lacan ${ }^{22}$ vem nos lembrar das cerimônias rituais que ocorriam nas sociedades mais primitivas - potlach - quando eram destruídos bens de consumo ou bens de representação e de luxo. Tais práticas destrutivas eram chamadas de prestígio, uma vez que elas eram manifestações gratuitas. A sociedade contemporânea ainda apresenta um vestígio social desse ritual de destruição, manifestado por meio de inexplicáveis acidentes e retornos a selvagerias, embora estejam necessariamente vinculados à progressão do nosso discurso. 


\section{Referências}

1. Winnicott DW. Processus de maturation chez l'enfant. Paris: Payot; 1970.

2. Freud S. Escritores criativos e devaneios. Rio de Janeiro: Imago; 1969.

3. Freud S. Formulações dos dois princípios do funcionamento mental. Rio de Janeiro: Imago; 1969.

4. Ostrower F. Criatividade e processos de criação. Petrópolis: Vozes; 1987.

5. Sousa ELA. Trabalhos invisíveis. In: Associação Psicanalítica de Porto Alegre, organizadora. 0 vaIor simbólico do trabalho e o sujeito contemporâneo. Porto Alegre: Artes e Ofícios; 2000.

6. Bergson H. M atéria e memória: ensaio sobre a relação do corpo com o espírito. São Paulo: Martins Fontes; 1999.

7. Passeron R. Pour une philosophie de la creation. Paris: Klincksieck; 1989.

8. Santos BS. Subjetividade, cidadania e emancipação. In: Santos BS. Pela mão de Alice. São Paulo: Cortez; 2001. p. 235-280.

9. Guattari F. As três ecologias. 10a ed. Campinas: Papirus; 1990.

10. Santos BS. Por uma concepção multicultural de direitos humanos. Revista Crítica de Ciências Sociais 1998; 48: 11-32.

11. Santos BS, Arriscado JN. Para ampliar o cânone do reconhecimento da diferença e da igualdade. In: Santos BS, organizador. Reconhecer para libertar: os caminhos do cosmopolitismo multicultural. Rio de Janeiro: Civilização Brasileira; 2003.

12. Momberger CD. Les histoires de vie: de l'invention de soi au projet de formation. Paris: Anthropos; 2000.

13. Santos BS, Rodriguez C. Para ampliar o cânone da produção. In: Santos BS, organizador. Produzir para viver: os caminhos da produção não capitalista. Rio de Janeiro: Civilização Brasileira; 2002. p. 23-77.
14. Bauman Z. M odernidade líquida. Rio de Janeiro: Jorge Zahar; 2001.

15. Frazão J. Cronologia e bibliografia. In: Naves R, organizador. Farnese de Andrade. São Paulo: Cosac \& Naify; 2002.

16. Frazão J. Siron Franco - Pinturas em Série [dissertação]. Rio de Janeiro (RJ): UFRJ; 1998.

17. Dawn A. Figuras e semelhanças: Siron Franco - pinturas 1968/1995. Rio de Janeiro: Índex; 1995.

18. Morais F. Frans Krajcberg: revolta. Rio de janeiro: GB Arte; 2000.

19. Becker HS. M étodos em pesquisa de ciências sociais. São Paulo: Hucitec; 1994.

20. Velloso MP. Criatividade e resíduos resultantes da atividade humana: da produção do lixo à nomeação do resto [tese]. Rio de Janeiro (RJ): Escola Nacional de Saúde Pública Sergio Arouca, Fundação Oswaldo Cruz; 2004.

21. Bauman Z. Vidas desperdiçadas. Rio de Janeiro: Jorge Zahar; 2005.

22. Lacan J. A ética da psicanálise. In: Lacan J. 0 Seminário Livro 7. Rio de Janeiro: Jorge Zahar; 1997.

Artigo apresentado em 03/03/2009

Aprovado em 21/08/2009 